\title{
Tribological Properties of Brass Surfaces Machined by Abrasive - Free Ultrasonic Finishing Process
}

\begin{abstract}
Zdeněk Aleš ${ }^{1}$, Jindřich Pavlů ${ }^{1}$, Monika Hromasová2 ${ }^{2}$ Jaroslava Svobodová ${ }^{3}$
${ }^{1}$ Czech University of Life Sciences Prague, Faculty of Engineering, Department for Quality and Dependability of Machines, Kamycka 129, 16521 Prague 6, Czech Republic. E-mail: ales@tf.czu.cz, jindrichpavlu@seznam.cz

${ }^{2}$ Czech University of Life Sciences Prague, Faculty of Engineering, Department of Electrical Engineering and Automation, Kamycka 129, 16521 Prague 6, Czech Republic. E-mail: hromasova@tf.czu.cz

${ }^{3}$ Jan Evangelista Purkyne University in Usti nad Labem, Faculty of production technology and management, Department of Technologies and Materials Engineering, Pasteurova 3334/7, 40096 Usti nad Labem, Czech Republic. E-mail: svobodova@fvtm.ujep.cz
\end{abstract}

\begin{abstract}
Brass mechanical properties are not ideal, particularly when the brass is exposed to the effects of mechanical wear. Final finishing of functional surface of machine component is substantial for the particular choice of brass. The aim of the research was to approve or disapprove the hypothesis if abrasive - free ultrasonic finishing (bufo) of brass has higher wear resistance of surface compared to the classical machining. The results of the experiment showed that abrasive - free ultrasonic finishing (bufo) has a major impact on the size of the elliptical wear area. Surface finishing by classic machining formed on average a $41 \%$ larger elliptical wear area compared to surface with abrasive - free ultrasonic finishing. The hypothesis of experiment were verified and it is possible to consider that abrasive - free ultrasonic finishing (bufo) has considerable influence on wear resistance of the surface of machine parts.
\end{abstract}

Keywords: Friction Wear, Abrasive - Free Ultrasonic Finishing, Wear Particles.

\section{Introduction}

Surface preparation is an important factor for the practical application of machine components, particularly in situations such as the precise alignment and high strength applications. It is necessary to pay attention to optimization of machining process. Influence of machining is a significant factor affecting the life of machine components within various applications.

In general, a hobbing, a lapping, a honing, a shaving and some advanced processes such as an electrochemical honing are some of the popular processes used in finishing of gear. The major disadvantages of these processes are that they suffer from a low finishing rate and a high equipment cost. Therefore, there is a need for an alternate process which has the capability of nanolevel finishing at higher finishing rate. A possibility is to use the ultrasonic finishing of the material. An improvement of the surface roughness compared to the abrasive finishing occurs at the use of the ultrasound [1]. The ultrasonic assisted abrasive flow machining is a new process in which the workpiece is subjected to ultrasonic vibration perpendicular to the medium flow direction. The fundamental mechanism of the ultrasonic machining is a material removal by means of the propagation of minute cracks that are inherently present in such material. One of possibilities of improving the machined surface quality is a method of abrasive-free ultrasonic finishing of metals. This method is used namely as a finishing operation after the turning. A principle is based on generating of ultrasonic waving. A vibrating system deforms the surface layers of the machined part in a plastic way [2].

As result of contact of friction surfaces leads to undesirable wear [3]. Wear resistance belongs among very im- portant characteristics of all materials including composite materials based on brass [4]. Wear is a permanent adverse change on the surface or dimensions of rigid bodies, caused by the interaction of functional surfaces, or functional surface and medium, which causes wear. Wear occurs as a removal or relocation of particular matter from the surface by mechanical effects, sometimes accompanied by other factors, such as chemical or electrochemical [5]. Generally, there can be classified six basic types of wear: adhesive, abrasive, erosive, cavitation, vibration and fatigue. The main types of wear of the lubricated surfaces is adhesive (sliding particles), abrasive (cutting particles) and fatigue (fatigue particles) wear [6].

The aim of the research was is to prove or disprove the hypothesis that abrasive - free ultrasonic finishing (bufo) of brass has significant influence on surface wear resistance compare to the classical machining. In order to describe machined surface there was used measurement of surface roughness, hardness HBW 2.5/187.5 and results of microscopy. With the intention of determining resistance of machined surface standardized test Reichert M2 tester was used. Number of wear particles and their morphology were analysed by automatic particle counter LaserNet Fines-C.

\section{Materials and methods}

A tested material was the brass $\mathrm{CuZn} 40$. Brass consisted $37.64 \% \mathrm{Zn}$ and $60.45 \% \mathrm{Cu}$, and other elements. This is a two-phase brass consisting of phases $\alpha$ and $\beta^{\prime}$. Analysis of the microstructure was carried out using a confocal laser microscope and SEM. For the purposes of the experiment 4 rollers were made by lathe cutting. Test rollers have size dimension of diameter $D=12 \mathrm{~mm}$ and length $l$ $=18 \mathrm{~mm}$. 
Below there are described options of different procedures of machining:

-Sample no. 1 - machining by turning, cutting speed was 785 rev. $\mathrm{min}^{-1}$, feed knives $0.04 \mathrm{~mm} \cdot \mathrm{rev}^{-1}$, cutting depth $0.5 \mathrm{~mm}$. Process liquid Avitol 2 was used during turning.

-Sample no. 2 - same machining by turning was used as for Sample no. 1. Abrasive-free ultrasonic finishing was also used as machining technology. Ultrasonic set I4 was used for research. This device is composed of the ultrasonic generator (power output $630 \mathrm{~W}$ and a working frequency of $22 \mathrm{kHz} \pm 10 \%$ ), the cutting speed of 40 rev. $\mathrm{min}^{-1}$, feed rate $0.07 \mathrm{~mm} \cdot \mathrm{rev}^{-1}$.

-Sample no. 3 - same machining was used as for Sample no. 2. Solution (25\% nanopowder $\mathrm{CuNi}$ and industrial oil meet the standards GOST 7580-91) was applied during machining with abrasive-free ultrasonic finishing technology.

-Sample no. 4 - same machining was used as for Sample no. 2. Solution (15\% nanopowder $\mathrm{MoS}_{2}$ and industrial oil meet the standards GOST 7580-91) was applied during machining with abrasive-free ultrasonic finishing technology.

The aim of the measurements was to assess the impact of technologies under consideration of possible surface hardening. Material hardness HBW 2.5/187.5 was measured on the surface of the sample in compliance with ISO 6506-1. Testing equipment (ball) was loaded by force $1.839 \mathrm{kN}$. Roughness parameters were measured using a portable profilometer Mitutoyo Surftest 301. Border wavelength cut-off was set at $0.8 \mathrm{~mm}$. A hundred different locations were measured. The test parameters of the surface roughness were $R a$ and $R z$ parameter.

Based on appropriate analysis of wear particle morphology (for example using a laser particle analyser LaserNet Fines-C), there can be determined what kind of wear is in progress on functional surfaces and if there is a risk of breakdown failure. Simultaneously, it is possible to use other appropriate tribological methods in order to determine technical condition of lubricating oil. Based on results of these analyses it can be decided whether lubricating oil can be still used or if it is necessary to change it.

Reichert tester M2 (Fig. 1) belongs to a group of devices which simulates real frictional contact. Frictional contact is evaluated (according to standards of Petrotest company) by load carrying capacity of lubricating film. Test roller is firmly clamped and pushed by weight on the rotating slip ring (made of specially alloyed steel). The lower third of the slip ring is immersed in the oil bath. Sufficient quantity of oil is fed into contact with the test roller during rotation of slip ring. The better lubricity of the lubricant is, the smaller elliptical wear area on the test roller is formed. Besides Reichert tester it is possible to use Four-ball wear test in order to assess tribological properties of certain lubricant or frictional surface [7]. The size of elliptical wear area $A$ is calculated according to the equation number 1 .

$$
A=\pi \cdot \frac{l}{2} \cdot \frac{d}{2}=0.785 \cdot l \cdot d\left[\mathrm{~mm}^{2}\right],
$$

Where:
A - elliptical wear area $\left[\mathrm{mm}^{2}\right]$;

1 - length of elliptical wear area $[\mathrm{mm}]$;

$\mathrm{d}$ - width of elliptical wear area [mm].

Range and measurement accuracy are determined by the used measuring device of length 1 and width $d$ of elliptical wear area A, which evaluates load carrying capacity of lubricating film. Each test roller was used six times in order to create elliptical wear area. Industrial oil MOGUL $90 \mathrm{H}$ was used for creation of each elliptical wear area.

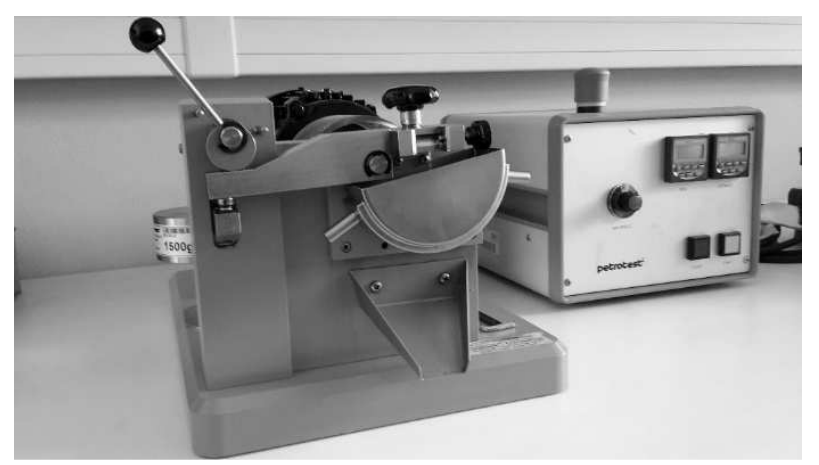

Fig. 1 Reichert Friction and Wear Tester.

In order to determine the number and type of particles in lubricating oil there can be used desktop particle counter and particle shape classifier LaserNet Fines-C (Fig. 2). This analytical equipment can analyse the hydraulic fluids and other lubricating oils from different types of machinery and results of analysis is capable to assess their current technical condition and suggest possible measures for their maintenance. Observation is based on an evaluation of morphology (particles greater than $20 \mu \mathrm{m}$ ) and wear particles number generated during the operation of machinery and equipment. In terms of morphology device recognizes three kinds of wear particles according to the type of wear: adhesive wear - severe sliding particles, abrasive wear - cutting particles, and fatigue wear - fatigue particles. LaserNet Fines-C consists of two components. The first part is the analyser, which analyses taken samples, the second part is a personal computer, which is necessary to analyse and evaluate data from the analyser [8].



Fig. 2 Particle counter and shape classifier LaserNet Fines-C.

Preparation of oil sample for analysis is thorough agitation and removal of air bubbles in an ultrasonic bath. The analysis is performed after removing the sample from the bath and entering the necessary data about oil sample 
to computer. The analysis takes about three minutes and results of analysis are displayed to the operator of the analyser after the evaluation of the oil sample.

In order to observe surface of elliptical wear area measurement it was necessary to use proper analytical tool. In general scanning electron microscopy (SEM) and transmission electron microscopy (TEM) are two main tools used for imaging particles or warn surfaces. Both instruments, if equipped with energy-dispersive x-ray spectroscopy (EDS), can give information on the chemical composition of the particles, discriminating those of interest from contaminants and residues. Furthermore, SEM and TEM can collect other information that can be used to better understand the wear mechanism that created the particles. It should be noted that SEM and TEM can provide complementary data. SEM can be used to obtain information about the surface topography of the particles, and TEM can be used to understand the crystallinity and thus the phase composition of the constituent alloy. Both instruments provide images containing size and shape information. [9]

For the purpose of the experiment, Tescan Mira 3 GMX SEM (scanning electron microscopy) was used. For measurement was used SE detector, the accelerating voltage was $20 \mathrm{kV}$ and operating distance was $15 \mathrm{~mm}$, and magnification was $87 \mathrm{x}, 96 \mathrm{x}$ and $667 \mathrm{x}$.

Statistical hypothesis of measured data sets were tested by program STATISTICA as well. The validity of the null hypothesis $\left(H_{0}\right)$ shows that there is no statistically significant difference $(P>0.05)$ among test datasets. Conversely hypothesis $H_{l}$ negates the null hypothesis, which is that between the test data sets is a statistically significant difference or dependence between variables $(P$ $<0.05)$.

\section{Results and discussion}

Results of surface hardness HBW 2.5/187.5 of the test samples are graphically shown in Fig. 3. From the results is clear that higher values of surface hardness HBW 2.5/187.5 were achieved on variants no. 2,3 and 4, i.e. using the technology abrasive-free ultrasonic finishing. The surface hardness HBW 2.5/187.5 was increased in interval $3.4-6.0 \%$.

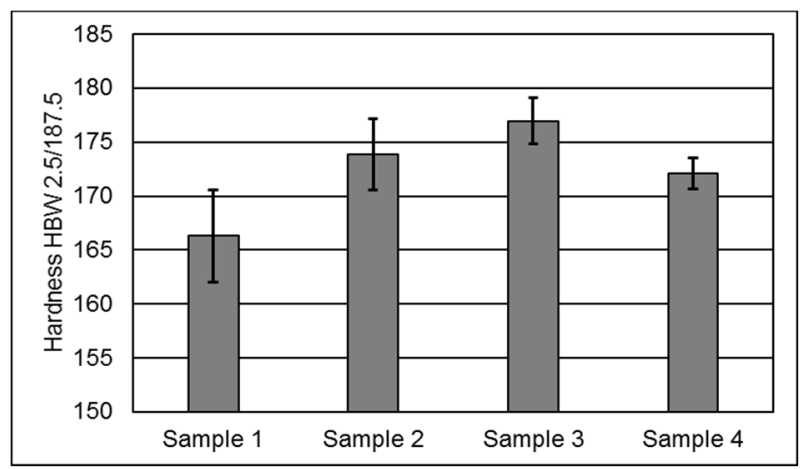

Fig. 3 Dependence of hardness HBW 2.5/187.5 on machining method.

In terms of the influence of variation of experiment on hardness HBW 2.5/187.5, i.e. variant of machining, the results of $A N O V A F$-test are follows:
When comparing variants 1 to 4 , hypothesis $H_{0}$ was not confirmed on the surface hardness HBW 2.5/187.5 $(P=0.0000)$, i.e. there is the difference in the level of significance of 0.05 among the tested variants of machining no. 1 to 4 .

When comparing variants 2 to 4 , hypothesis $H_{0}$ was not confirmed on the surface hardness HBW 2.5/187.5 ( $P$ $=0.0000)$, i.e. there is the difference in the level of significance of 0.05 among the tested variants of machining no. 2 to 4 .

Graphical presentation of the results of surface roughness are shown in Figs. 4 - 5. The results show that significantly lower values of surface roughness were achieved by the variants no. 2, 3 and 4, i.e. using the technology abrasive-free ultrasonic finishing. Parameter of roughness $R a$ was reduced about $94 \%$ for variants no. 2, 3 and 4 beside variant no. 1 . The parameter of roughness $R z$ of variants no. 2, 3 and 4 was reduced about $92 \%$ beside variant no. 1 .

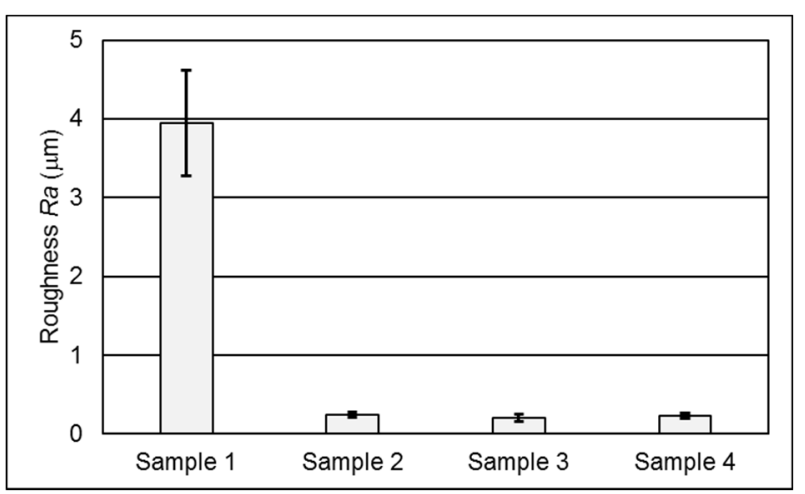

Fig. 4 Results of dependence of surface roughness $R a$ on machining method.



Fig. 5 Results of dependence of surface roughness $R z$ on machining method.

In terms of the influence of variants of experiment on roughness, i.e. variants of machining, the results of ANOVA F-test are as follows:

When comparing variants 1 to 4 , hypothesis $H_{0}$ was not confirmed on the surface roughness $R a(P=0.0000)$ and $R z(p=0.0000)$, i.e. there is the difference in the level of significance of 0.05 among the tested variants of machining no. 1 to 4 . Hypothesis $H_{l}$ was confirmed.

When comparing variants 2 to 4 , hypothesis $H_{0}$ was confirmed for parameter of surface roughness $R a$ $(P=0.5107)$ and $\operatorname{Rz}(P=0.6935)$, i.e. there is not the difference in the level of significance of 0.05 among the tested variants of machining no. 2 to 4 . 
Fig. 6 shows measured elliptical wear area $A$ with standard deviation created by Reichert tester M2 (six measurements for each test roller).

From the experiment results it is obvious that the elliptical wear area $A$ decreased at variants No. 2 to 4 up to $2.89 \pm 5.88 \%$. The highest decrease $39.55 \%$ was set at the sample 3 .

Measured values indicate that the largest elliptical wear area is at the sample 1. Conversely, the smallest elliptical wear area was measured in sample 3. From these measured values it is possible to conclude that sample 3 is the best in case of resisting to specified load. It is necessary to note that the sample 1 was machined a standard way. It can be assumed that the surface roughness contributed to the erasure lubricating process and thus to decreasing intensity of wear.



Fig. 6 Size of elliptical wear area A.

Each sample of oil MOGUL 90H used during the creation of an elliptical wear area was analysed with particle counter LaserNet Fines, to determine the number and morphology of wear particles. The sample of lubricating oil from Reichert tester was analysed. Based on previous research, according to the results of repeatability test it can be inferred that used LNF-C instrument have comparable repeatability as similar instruments of his kind [10].

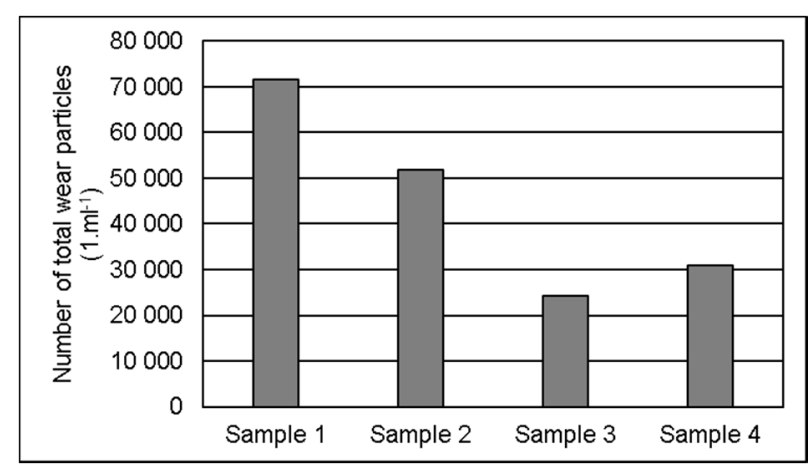

Fig. 7 Total number of wear particles.

Measured values indicate that the highest number of wear particles was at the sample 1. Conversely, the lowest number of wear particles was measured in sample 3 (Fig. 7). From the perspective of morphology of the metal particles (cutting, severe sliding, fatigue) larger than $20 \mu \mathrm{m}$, it was observed a similar trend as the total number of particles (Fig. 8). The absolute maximum number of particles was recorded in sample 1 which was 585 fatigue particles presented in $1 \mathrm{ml}$. The highest level of fatigue particles was caused by a particular type of machining.

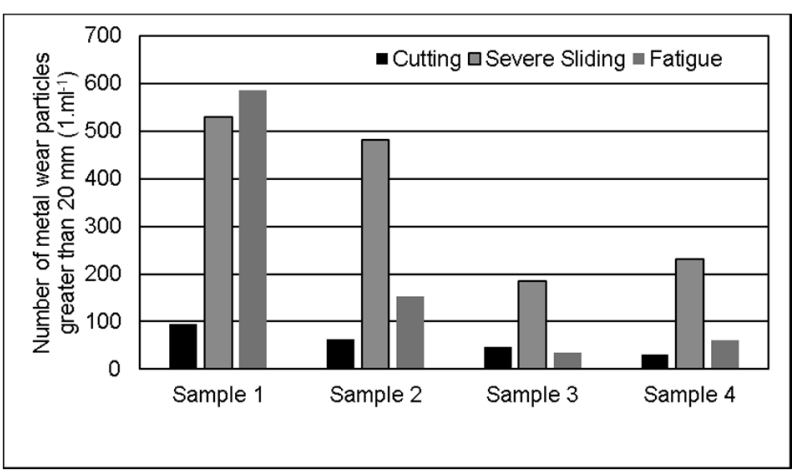

Fig. 8 Number of particles greater than $20 \mu \mathrm{m}$ (cutting, severe sliding, fatigue).

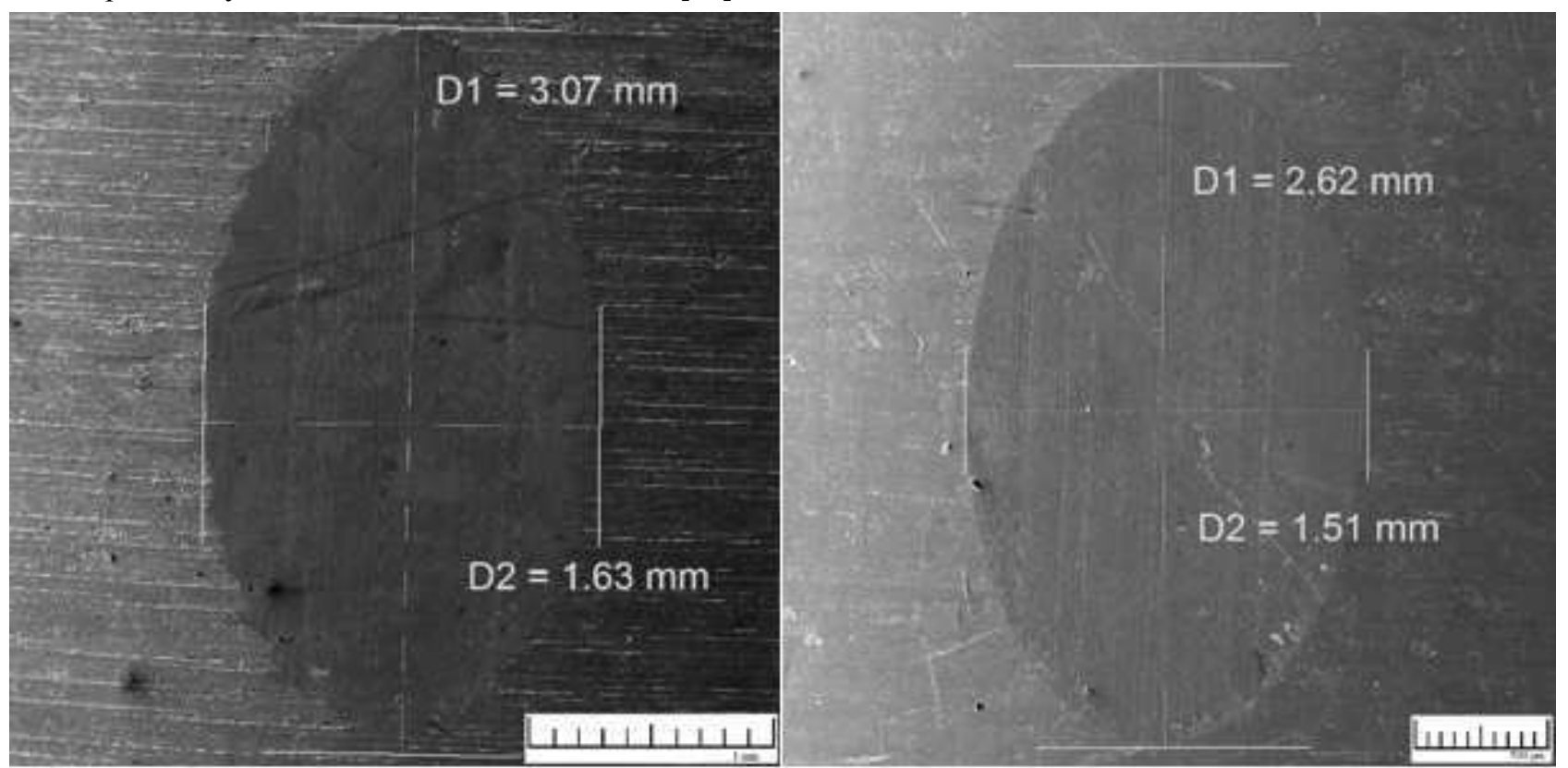

Fig. 9 SEM images - Comparison of two elliptical wear areas (left image - Sample 1-scale 1mm, right image - Sample 2 - scale $500 \mu \mathrm{m})$. 
The presence of fatigue particles in lubricating systems poses a risk in terms of accelerated wear of lubrication points. As it was stated, sample 1 had the highest level of fatigue particles in $1 \mathrm{ml}$. It means that this sample could not resist to specified load compared with other samples. Conversely, in the context of considered new ways of machining sample 3 withstood the best, because it contained only 34 fatigue particles presented in $1 \mathrm{ml}$.

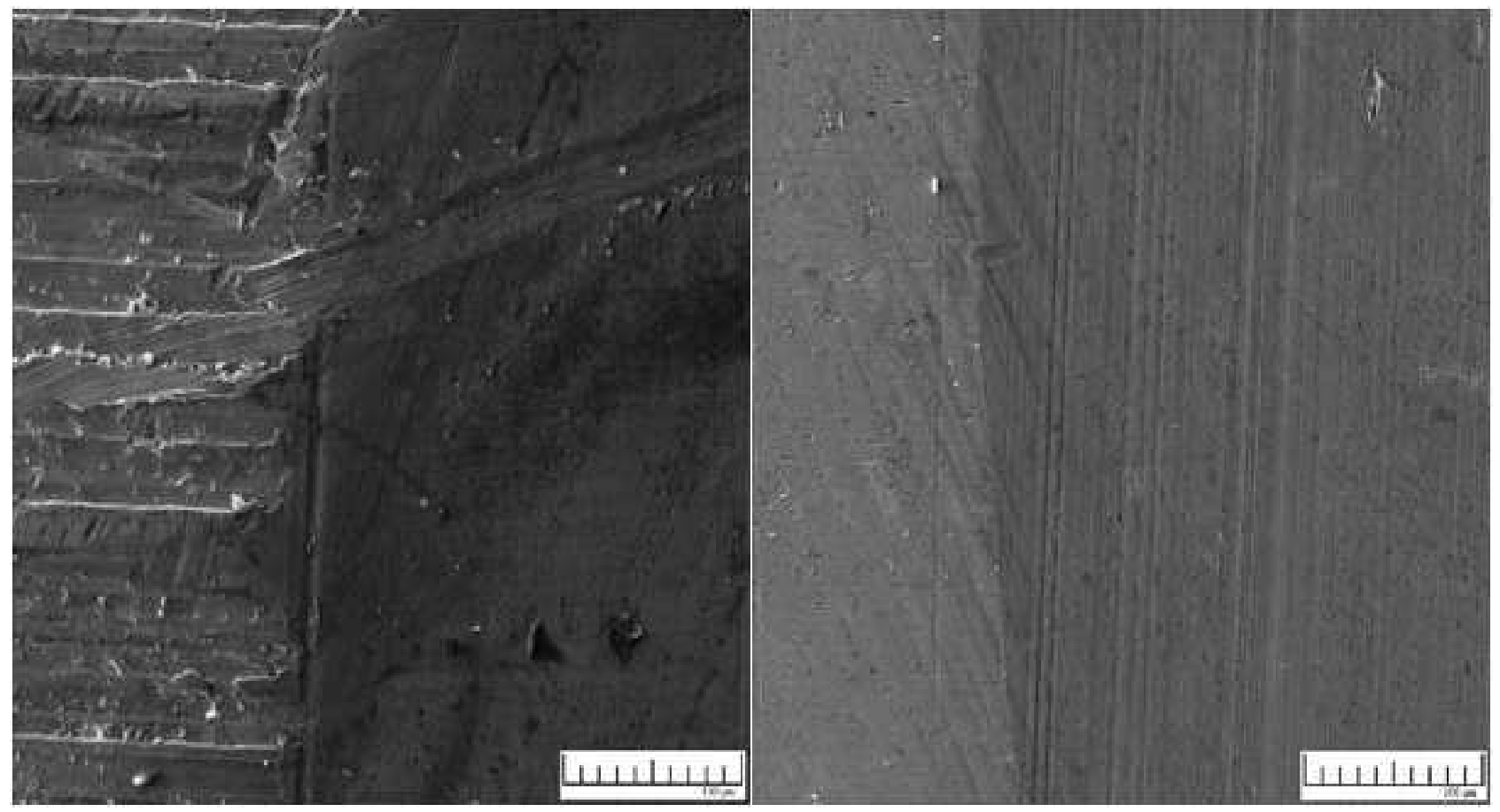

Fig. 10 SEM images - Comparison of two edges between surface and elliptical wear area (left image - Sample 1 - scale $100 \mu \mathrm{m}$, right image - Sample 3 - scale $100 \mu \mathrm{m}$ ).

Elliptical wear area can be evaluated by use of the scanning electron microscopy [11]. Fig. 9 clearly shows the difference between the sizes (including dimensions) of two elliptical wear areas. Left SEM image clearly shows the size of the elliptical wear area and surface typical for classical machining (higher roughness). Picture left shows the size of elliptical wear area and surface after machining with technology abrasive-free ultrasonic finishing (lower roughness and higher hardness). Fig. 10 shows closer view of two edges between surface and elliptical wear area.

Previous experiment which was focused on steel steel contact showed opposite results. According to different research [12] addition of alumina nanoparticles to the $\mathrm{Cu}-\mathrm{Zn}$ alloy, the quantities of the coefficient of friction (COF) and weight loss rate were reduced by $20 \%$ and $40 \%$, respectively.

Other method for assessing wear intensity might be based on simple wear algorithm based on subsurface stress calculation which was introduced and validated using experimental data on the wear particles size. The particle generation criterion was based on a critical stress and geometrical boundary conditions. It was shown how that model works for steel-steel contact and steel-brass contact. [13]

The advantage of lower wear of machine parts is also related to lower formation of abrasive particles, which consequently contaminate lubricant. Lower particle contamination is also beneficial in lower requirements for lubricant cleaning and regeneration in general. [14]

\section{Conclusions}

The results of experiment show that technology abrasive-free ultrasonic finishing has a significant impact on the overall surface resistance to wear (Fig. 6). Compared to classical machining it is apparent that technology abrasive-free ultrasonic finishing moreover achieves better results in terms of lower roughness and a higher hardness of the surface (Figs. 3-5). The best results reached the sample 3, which was machined with support of Solution (25\% nanopowder $\mathrm{CuNi}$ ). In terms of particles morphology, technology abrasive-free ultrasonic finishing has favorable effect because it does not form abrasive and fatigue particles (Fig. 8) which are more dangerous compared to severe sliding particles. The results of analyses were appropriately supplemented with SEM images (Figs. 9, 10).

It may be concluded that the hypothesis was proven that technology abrasive - free ultrasonic finishing (bufo) of brass has significant influence on surface wear resistance compare to the classical machining. Thus, the machined surface may find application for example in highly stressed plain bearing of machines not only in the industry field, but also in agriculture.

\section{Acknowledgement}

The paper was created with the grant support - CZU: 31190/1484/314802; MPO: FV20286 - Maintenance management information system with benchmarking module respecting Industry 4.0. 


\section{References}

[1] SVOBODOVÁ, J., KRAUS, P., MÜLLER, M., LEBEDEV, A., YUROV, A., LEBEDEV, P. (2015). Influence of cutting fluid on abrasive-free ultrasonic finishing of aluminium alloy. In: Manufacturing Technology, Vol. 15, pp. 710-714.

[2] MÜLLER, M., LEBEDEV, A., SVOBODOVÁ, J., NÁPRSTKOVÁ, N., LEBEDEV, P. (2014). Abrasive-free ultrasonic finishing of metals. In: Manufacturing Technology, Vol. 14, pp. 366-370.

[3] CHOTĚBORSKÝ, R., LINDA, M. (2016). Determination of chemical content of soil particle for abrasive wear test. In.: Agronomy Research, Vol. 14, pp. 975-983.

[4] VALÁŠEK, P., RUGGIERO, A., MÜLLER, M. (2017). Experimental description of strength and tribological characteristic of EFB oil palm fibres/epoxy composites with technologically undemanding preparation: In.: Composites Part B: Engineering, Vol. 122, pp. 79-88.

[5] MIKUŠ, R., SZABÓ, V., DRLIČKA, R., BAKAJOVÁ, J. (2014). Hardness and microstructure analysis of deposit material based on Fe-Cr-Ni. In.: Advanced Materials Research, Vol. 1059, pp. 35-42.

[6] VESELA, K., PEXA, M., MARIK, J. (2016). Change viscosity of the engine oil when using e85 fuel: In.: Listy cukrovarnické a řepařské, Vol. 132, pp. 241-245.

[7] RUGgiero, A., D'AMATO, R., MEROLA, M., VALÁŠEK, P., MÜLLER, M. (2017). Tribological characterization of vegetal lubricants: Comparative experimental investigation on Jatropha curcas L. oil, Rapeseed Methyl Ester oil, Hydrotreated Rapeseed oil. In: Tribology International, Vol. 109, pp. 529-540.

[8] VESELA, K., PEXA, M., MARIK, J. (2013). Analysis of particle abrasive wear of engine oil when using lasernet fines analyser. In: Proceeding of TAE 2013. Eds.: Malaták, J., Libra M., pp. 637641, Prague, Czech University of Life Sciences Prague.

[9] FABRIZIO, B., BENYA, P., EBRAMZADEH, E., CAMPBELL, P., CHAN, F., MCKELLOP, $\mathrm{H}$. A. (2009). Metal wear particles: What we know, what we do not know, and why. In: SAS Journal, Vol. 3(4), p. 133-142.

[10] PETERKA, B., NOVOTNÁ, Z., JINDRA, P. (2013). Statistical evaluation of data obtained by particle counter using non-reference fluids: In: Proceeding of TAE 2013. Eds.: Malaták, J.,. Libra M., pp. 518-522, Prague, Czech University of Life Sciences Prague.

[11] HEINRICHS, J., OLSSON, M., JENEI, I. Z., JACOBSON, S. (2014). Transfer of titanium in sliding contacts-new discoveries and insights revealed by in situ studies in the SEM. In: Wear, Vol. 315, No. 1-2, pp. 87-94.

[12] BAGHANI, M., ALIOFKHAZRAEI, M., ASKARI, M. (2017). $\mathrm{Cu}-\mathrm{Zn}-\mathrm{Al} 2 \mathrm{O} 3$ nanocomposites: study of microstructure, corrosion, and wear properties. In.: International Journal of Minerals, Metallurgy, and Materials, Vol. 24, No. 4, pp. $462-472$.

[13] AKCHURIN, A., BOSMAN R., LUGT, P. M. (2016). A Stress-Criterion-Based Model for the Prediction of the Size of Wear Particles in Boundary Lubricated Contacts. In: Tribology Letters, Vol. 64, No. 3, pp. 1-12.

[14] HYBSKA, H., VELKOVA, V., SAMESOVA, D., FIALOVA, J., KUCERA, M. (2018). Study of the regeneration cleaning of used mineral oils - ecotoxicological properties and biodegradation. In: Chemical and Biochemical Engineering Quarterly, Vol. 31, No. 4, pp. 487-496. 